\title{
O protagonismo Autista na escola: uma proposta de artefato que estimule a contação de histórias e a formação de laços verdadeiros
}

The Autistic protagonism at school: a proposal of a storytelling artifact that enables the formation of true bonds

\author{
Raquel Pereira Pacheco, Tiago Barros Pontes e Silva
}

autismo, inclusão, educação, contação de histórias

\begin{abstract}
A proposta do presente relato é discutir a confecção de um artefato que auxilie a expressão autônoma, consentida e verdadeira de crianças, em especial as neuroatípicas, que permita compartilhar histórias significativas com diferentes pessoas, possibilitando a formação de laços, por meio de sua manipulação e interferência. A partir de revisões de literatura e entrevistas semiestruturadas, foi possível mapear um recorte do contexto da educação inclusiva em Brasília, em especial com crianças e adolescentes autistas. A partir da síntese de requisitos e a inspiração em autores autistas como Grandin, Lawson, Zucher-long e Fleischmann, o compartilhamento de narrativas e a voz ativa para contar histórias foi definido como o principal ponto de destaque do sistema a ser projetado. O sistema proposto pode sofrer interferência de diversos atores, e pode evoluir organicamente se adequando às necessidades que surjam a partir do momento de sua implementação.
\end{abstract}

autism, inclusion, education, storytelling

The purpose of this report is to discuss the creation of an artifact that helps the autonomous, consent and true expression of children, especially the neuroatypical ones, allowing the sharing of meaningful stories with different people, enabling the formation of bonds through its manipulation and interference. From reviews of literature and interviews, it was possible to map a piece of the context of inclusive education in Brasilia, especially with autistic children and adolescents. From the design synthesis and inspiration in autistic authors such as Grandin, Lawson, Zucher-long and Fleischmann, the narrative sharing and the active voice for storytelling has been defined as the main highlight of the system. The proposed system can be influenced by several actors, and can evolve organically to suit the needs that arise from the moment of its implementation.

\section{A Escola do século XXI?}

O conceito de educação sofreu diversas mudanças ao longo dos séculos, hoje apresentando uma dicotomia de significados: o processo de desenvolvimento de um indivíduo, que ultrapassa o sistema formal de aprendizagem, e a socialização deste indivíduo em uma determinada civilização (Vianna 2006). Enquanto temos teóricos como Piaget (Ivic 2010) e Rogers (1983) que defendem que as relações de ensino-aprendizagem devem se pautar no desenvolvimento do aprendiz, nossa herança histórica moldou as escolas de forma a buscar adequar esse indivíduo para a sociedade, suprimindo suas inadequações e moldando-o enquanto perfil de cidadão desejável.

As reformas ocorridas após o golpe de 64 no Brasil tiveram como principal objetivo formatar uma escola racionalizada, com foco em eficiência e produtividade, visando a um maior desenvolvimento do país e resposta às demandas de mercado. Este foi um dos principais legados do século XX para a educação brasileira, em específico para a estruturação do sistema escolar público (Saviani 2014). A escola como meio de produtividade para assegurar a expansão econômica do país foi inspirada em debates do século XIX nos países desenvolvidos, porém só foi implementada em nosso país no final do século XX. Tivemos então, uma acumulação do déficit histórico, moldando a escola que formaria nossos cidadãos em ideais de um século que já havia passado. A escola hoje, enquanto um mecanismo de adequação à sociedade, perpetua modelos mentais de dois séculos atrás (Pacheco 2016; Saviani et al. 2014).

Assim, o desafio presente é transitar entre esses dois conceitos e esses dois resultados -

Anais do $8^{\circ} \mathrm{CIDI}$ e 8 CONGIC

Guilherme Santa Rosa; Cristina Portugal (orgs.)

Sociedade Brasileira de Design da Informação - SBDI

Natal | Brasil | 2017

ISBN 978-85-212-1305-5
Proceedings of the $8^{\text {th }} \mathrm{CIDI}$ and $8^{\text {th }}$ CONGIC

Guilherme Santa Rosa; Cristina Portugal (orgs.)

Sociedade Brasileira de Design da Informação - SBDI

Natal| Brazil | 2017

ISBN 978-85-212-1305-5 


\section{CIDI 2017}

o próprio indivíduo e o desenvolvimento da sociedade - durante uma mudança para uma era inerentemente digital (Kurzweil 2005). O advento da tecnologia mudou as ferramentas que utilizamos e também mudou como nos relacionamos com o mundo. De acordo com Willis (2006), o mundo físico e digital ao nosso redor tem grande influência no modo que nos comportamos, enquanto indivíduos e enquanto comunidade. Quando nós construímos o mundo ao nosso redor, depois ele nos constrói de volta em um ciclo de feedback. Se a tecnologia muda, nossa capacidade para produzir bens e conhecimento também muda; as coisas que utilizamos no nosso dia-a-dia mudam; nossa percepção de tempo muda; nosso comportamento muda. O sistema escolar, portanto, também deve mudar.

De fato, observa-se que existem vários experimentos no Brasil (Sagrado, Perez \& Lima, 2014) e no mundo (Alves 2001) que buscam uma nova maneira de se compreender a escola. No entanto, essas escolas alternativas ainda não são acessíveis para grande parcela da população, principalmente por se tratarem de exceções dentro do sistema escolar. Ainda é necessário encontrar o equilíbrio entre a autonomia das escolas, a atenção à individualidade dos estudantes, a diversidade natural brasileira e a necessidade de implementação no sistema nacional para garantir uma menor desigualdade escolar.

Afirma-se, portanto, que hoje a educação formal não atende nem às expectativas da sociedade, nem as de seus estudantes. A sociedade mudou, mas a escola ainda não.

\section{Para quem é a escola?}

Em um contexto em que a escola molda seus estudantes durante pelo menos 13 anos, ao analisarmos a relação entre indivíduo e escola observamos que o modelo de educação formal que existe atualmente não é adequado para todos, pois existe pouca flexibilidade para aquilo que é tido como normal: um ensino massificado para o jeito neurotípico de aprender.

Entendemos que o modelo tradicional de ensino oferece uma experiência escolar homogênea para todos seus estudantes (Pacheco, 2016), representado simbolicamente pela Figura 1. Assim, os alunos fazem as mesmas disciplinas, em séries regulares, com a mesma duração, com os mesmos professores, assistindo às mesmas aulas e sendo avaliados da mesma maneira. Com isso, se torna evidente que nem todos os envolvidos se adequam a essa estrutura predeterminada (Lawson 2008; Pacheco, Eggertsdóttir \& Marinósson, 2007). Aqueles que não se encaixam dentro da estrutura, são frequentemente vistos como inadequados e suas características, que o distinguem dos outros, é logo tomada como desvantagem. Esses indivíduos vão passando pelo processo escolar sendo moldados dentro dessa cultura, tendo suas inadequações suprimidas.

Figura 1: Estudantes sendo representados por formas geométricas, com o intuito de representar suas diferenças; sendo encaixados em um molde único, simbolizando a experiência escolar igual. Fonte: PACHECO, 2016. p. 15
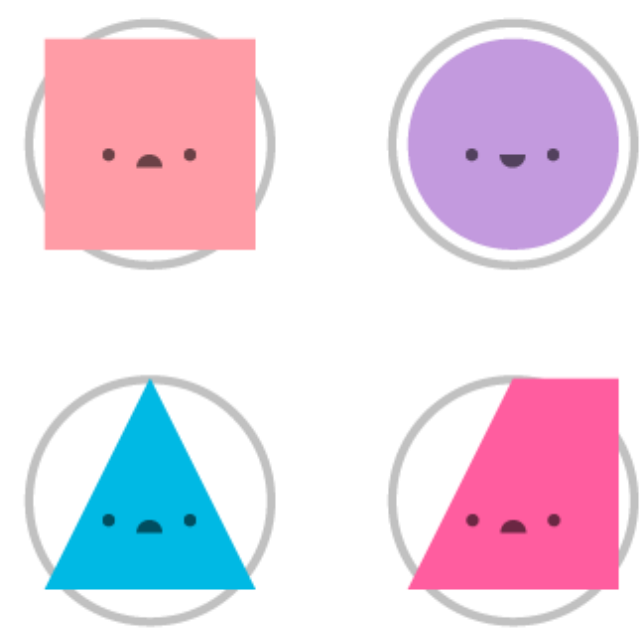


\section{CIDI 2017}

A partir dessa metáfora de formas e encaixes, pode-se direcionar uma discussão sobre inclusão. O discurso pode permear dois paradigmas: a medicalização ou a diversidade (Blume, 1998; Luengo, 2010). No primeiro deles, em um cenário medicalizante vê-se no indivíduo diferente uma necessidade de cura: dá-se a ele um rótulo, um diagnóstico que descreve uma patologia. Ele é, portanto, visto como deficiente ou doente: Ihe falta algo que todas as outras pessoas têm, ou há algo que não é considerado normal e que precisa ser expurgado. No último cenário, no qual haveria uma valorização da diversidade, pode-se enxergar as diferenças de maneira mais acolhedora, uma vantagem natural: uma comunidade com membros diversos em que há experiências e olhares diferentes sobre o mundo. Aqui, traz-se o termo neurodiversidade para representar os diferentes modos em que se pode ocorrer 0 desenvolvimento cognitivo. Deve-se entender ainda que esses indivíduos seriam aceitos pela sociedade, reforçando sua identidade própria e sua voz para compartilhar suas experiências (Solomon, 2013).

Para discutir neurodiversidade, traz-se aqui o autismo, que tem tido um aumento de diagnósticos no mundo inteiro (Rios et al. 2015). Esse aumento não tem causa definida, podendo ser explicado por uma maior amplitude no diagnóstico desde 2012, bem como um maior conhecimento sobre o autismo. Quaisquer que sejam as causas do aumento, é importante ressaltar que também aumenta o debate sobre o autismo e a relevância de ativistas como Grandin (2013) e Lawson (2008), que buscam falar da vivência autista e também analisar como essa condição interfere em sua relação com o mundo.

O autismo, também conhecido como Transtornos do Espectro Autista, engloba o Autismo investigado por Kanner (também chamado de autismo infantil), a Síndrome de Asperger e outros transtornos invasivos de desenvolvimento (McPartland, Klin, \& Volkmar, 2014). Trata-se de um transtorno complexo e se manifesta heterogeneamente (Hogenboom \& Woodward, 2013): vê-se indivíduos que não desenvolvem a comunicação verbal e outros indivíduos que conseguem se desenvolver de maneira mais próxima a seus pares neurotípicos, vivendo com bastante independência. Seu diagnóstico, na prática, é feito pela observação do comportamento ao longo do tempo, sendo que os primeiros sintomas se manifestam antes dos 3 anos de idade (Klin, 2006; McPartland et al., 2014). Suas características mais marcantes, que são inclusive descritas no diagnóstico, são: dificuldades na interação interpessoal, na comunicação e no desenvolvimento da linguagem; padrões repetitivos de comportamentos e interesses restritos, que implicam rituais e rotinas muito bem definidas; e algumas dificuldades de integração sensorial (Hogenboom \& Woodward, 2013).

Tendo em vista que sistema escolar ainda opera sob um paradigma medicalizante (Luengo, 2010), observamos que estudantes autistas possuem ainda muita dificuldade de adaptação nesse contexto.

\section{Um sistema para intervir na realidade escolar}

O primeiro passo para identificar oportunidades de intervenção dentro dessa realidade foi entender como esse sistema se configurava, partindo da criança autista e de suas interações com o mundo ao seu redor: a escola, a família, a comunidade e as instituições. Na Figura 2, está representado o sistema escolar com foco no indivíduo, ilustrando as intersecções das esferas da vida de um estudante autista (Pacheco, 2016). Observa-se que esse sistema é complexo e não trata a vida escolar de maneira isolada, sendo necessário, portanto, compreender a realidade deste indivíduo de forma holística. Não se deve reduzir a formação escolar somente ao com o desenvolvimento cognitivo ou à aquisição de conteúdo (Pacheco \& Silva, 2015) Deve-se estabelecer a criança como centro e protagonista do processo de aprendizagem, possibilitando também seu desenvolvimento físico-motor, afetivo e social (Gratiot-Alfandéry, 2010; Rogers, 1961, 1983). 
Figura 2: Mapa do sistema escolar tendo como centro o estudante autista. Estão representados: o ambiente doméstico, a comunidade, a escola especial, a escola inclusiva, os especialistas e as instituições. Fonte: PACHECO, 2016. p. 66

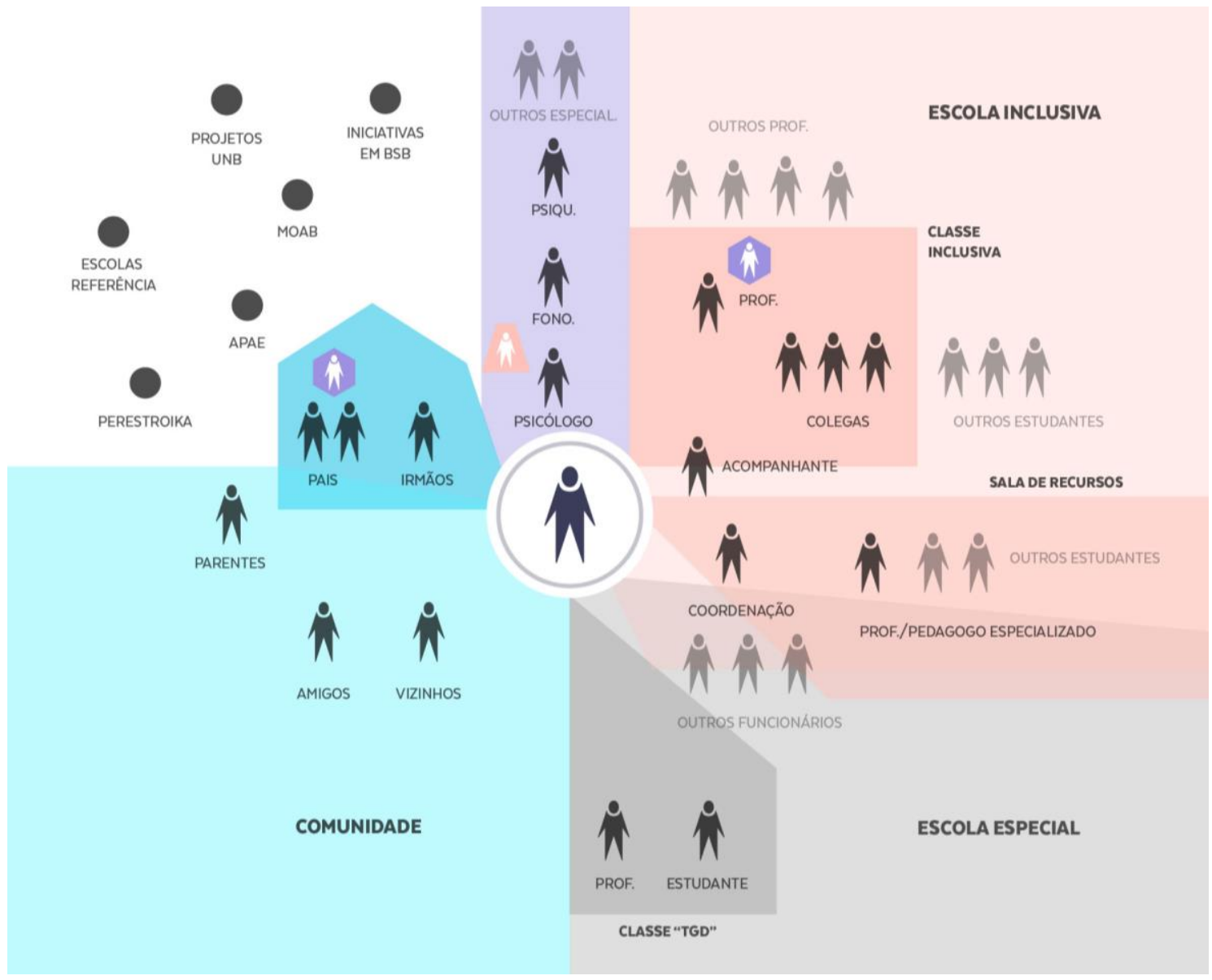

O mapa foi construído a partir das informações obtidas por entrevista com uma professora de história da rede pública de ensino. Utilizou-se o nome fictício Joana para facilitar o modo de contar suas vivências. Joana é educadora e mãe de uma criança autista, ela buscou se capacitar para entender melhor como ajudar o seu filho, bem como conhecer a realidade dos estudantes autistas nas escolas. Após conhecer o método Son-Rise, passou a aplicar técnicas do método com seu filho e em sala de aula também com seus estudantes neurotípicos. A partir do depoimento de Joana, foi levantado que existem duas possíveis experiências para um estudante autista: a escola inclusiva e a escola especial. Na escola inclusiva, o estudante é colocado em uma classe reduzida (com menos estudantes) e tem direito a um auxiliar pedagógico para acompanhá-lo no dia-a-dia. No caso das escolas especiais, o estudante frequenta uma classe com, no máximo, outro estudante e um professor. O estudante inicia sua jornada no tipo de classe mais adequado ao seu desenvolvimento.

A dificuldade em lidar com esses alunos, no entanto, cresce à medida que ele avança no sistema escolar. Tanto as classes especiais quanto o acompanhamento individual existem somente no Ensino Fundamental I (dos 6 aos 11 anos), bem como o direito legal a um auxiliar pedagógico. Quando a criança chega no Ensino Fundamental II (aos 11 anos em situação regular), ela teoricamente já estaria "adaptada ao sistema" e não precisa de apoio individual, tendo acesso somente à sala de recursos. Essa, no entanto, não é a realidade nas escolas regulares públicas. Raramente alunos autistas que possuem mais dificuldades em seu desenvolvimento cognitivo conseguem avançar no sistema escolar de fato, existindo casos de alunos que vão sendo empurrados para as séries mais avançadas por professores que tem pouco apoio para lidar com suas dependências e lacunas no aprendizado das séries passadas.

Os autistas que estão na faixa do espectro que conseguem desenvolver a comunicação verbal e possuem pouco comprometimento cognitivo, possuem o seu desenvolvimento afetado não mais pelo conteúdo, mas pelas habilidades sociais que não conseguiram adquirir durante 
esse período, muitas vezes não demonstrando interesse nenhum nos eventos da sala de aula. A presente pesquisa não se propõe a discutir as vantagens pedagógicas de quaisquer uma dessas classes, mas deve-se ressaltar que um dos valores principais desse projeto é entender os impactos da ausência de espaços exclusivos para autistas, a não ser que isso seja uma escolha consciente deles.

No processo de inclusão escolar tenta-se adequar esses indivíduos à realidade neurotípica. O estudante autista se une aos outros estudantes para ser também moldado pelo processo de escolarização massificada. Ao conversar com Joana, viu-se que existe uma dicotomia bastante interessante em relação a quanto o autista consegue se encaixar em uma comunidade "normal" (este termo está sendo utilizado para contrapor a uma comunidade diversa). À medida em que uma criança aparenta ter mais dificuldades (por exemplo: um autista não verbal), o professor tem maior autonomia na sala de aula e há menos cobrança de aquisição de conteúdo. $O$ desenvolvimento individual é favorecido e a escola se torna mais flexível. À medida em que uma criança, no entanto, aparenta ser neurotípico, seu diagnóstico se torna invisível, o professor logo tem uma menor autonomia para decidir sobre seu desenvolvimento e há uma maior cobrança da escola para que ela se encaixe junto aos demais.

Abre-se, a partir daí uma discussão sobre o que é normal. Podemos definir a normalidade como aquilo que é mais frequente em uma determinada sociedade, incluindo seus padrões de comportamento e hábitos (Lawson, 2008). Contudo, essa definição é considerada relativa: ao tempo, à cultura e aos indivíduos que formam essa comunidade. O que é normal em um grupo, pode não ser normal em outro. Vê-se, no entanto que ao aferir algo como não normal, implicase que este é inadequado (Luengo, 2010; Pacheco, 2016). Ao entender o sistema educacional como parte do processo de inserção de um cidadão funcional na sociedade, é possível argumentar que este sistema tem um grande papel na definição do que é a normalidade. Para contrapor a realidade adaptadora da escola, teóricos como Rogers $(1961,1983)$ falavam sobre a educação centrada no estudante, baseado em sua abordagem centrada na pessoa (ACP). $O$ modelo de baseia na empatia e na adaptabilidade do educador a seu aprendiz, e não o contrário. O objetivo, portanto, não é integrar pessoas com o sistema vigente, mas sim tornar o sistema mais acolhedor, empático e humano para todos (Pacheco et al., 2007)

Ao observar exemplos de ferramentas como o TEACCH (Tratamento e educação para crianças autistas e com distúrbios correlatos da comunicação, do inglês Treatment and Education of Autistic and Communication Handicapped Children) e o PECS (Sistema de comunicação por troca de figuras, do inglês Picture Exchange Communication System), inferese que elas não funcionam com a lógica da voz ativa do autista, mas sim para que haja uma dualidade de perguntas e respostas, ma qual, na maioria das vezes, o autista somente responde a perguntas. Ao trabalhar com crianças no contexto escolar, também é importante ressaltar que a comunicação tende a ser adultocêntrica: a criança autista deve aprender a se comunicar com um adulto neurotípico.

A intervenção projetada não visou focar somente nos estudantes ou exclusivamente nos professores, mas se concentrou em reforçar essas relações de uma maneira acolhedora e verdadeira. Buscou-se criar um recorte de aplicação para este projeto específico, mas o sistema projetado também deve permitir posterior desenvolvimento e expansão. Várias etapas de criação se voltaram para a confecção de um sistema mais abrangente, que englobaria diversos artefatos e serviços existentes, a partir de uma abordagem de design de serviços (Polaine, Løvlie \& Reason, 2013; Stickdorn \& Schneider, 2011). Partiu-se de várias ideias divergentes e simples até a concepção de um sistema complexo que compreenderia grande parte das relações levantadas sobre estudante autista.

Portanto, o sistema proposto consiste em: um meio de expressão (autônoma, consentida e verdadeira) que permita compartilhar histórias significativas com diferentes pessoas, possibilitando a formação de laços, por meio de sua manipulação e interferência.

Cada um desses pontos surge das dificuldades apontadas anteriormente em etapas de levantamento de informações:

- meio de expressão autônoma, consentida e verdadeira: o objetivo é dar voz ativa aos autistas, para que eles possam falar em seus próprios termos e quando eles tiverem vontade; 


\section{CIDI 2017}

- compartilhar histórias significativas: essa expressão precisaria agregar conteúdo além de objetos ou palavras simples, mas oferecer a estrutura para narrativas complexas. A dimensão das histórias pessoais acrescenta uma camada muito interessante a esse meio para que se formem laços verdadeiros, com base em criação e compartilhamento de significados (Kolko, 2011). Neste caso específico, as narrativas podem ser um modo de expressão, independente de serem reais, metafóricas ou fictícias;

- manipulação e interferência: esse meio precisa ser interativo, poder ser construído, desconstruído e construído. O sistema precisaria ser aberto o suficiente para haver intervenção, por qualquer um dos atores. Ele poderia ser construído sozinho ou em parceria com alguém, de modo que o indivíduo o manipulando pudesse liderar e guiar a comunicação caso ela o desejasse.

A estrutura utópica do sistema deve abarcar o contexto escolar e o contexto de desenvolvimento de projetos para o sistema escolar, com o intuito de viabilizar a proposta e desconcentrar os esforços. Afinal, se o sistema proposto pode ser refeito e reinterpretado, pode também possuir um crescimento orgânico. Assim, entende-se que o sistema projetado deve ser também open-source, visando facilitar sua distribuição. Nesse sentido, o projeto possui dois focos distintos:

1. Conscientizar e oferecer recursos sobre o autismo;

2. Auxiliar os autistas a compartilharem suas histórias.

A partir desses focos, é necessário entender melhor quais são as necessidades dos usuários de um sistema com esses objetivos. Buscou-se, a partir do mapa de atores, traçar perfis de usuários que podem ser atingidos pelo projeto. Dos atores mapeados, destacaram-se:

- Pais de autistas com pouca experiência e acesso a recursos;

- Professores com pouca experiência e acesso a recursos;

- Designers que querem intervir no contexto do autismo;

- Designers que querem intervir no contexto de inclusão.

Além desses atores, é preciso destacar também os próprios autistas, que devem continuar no centro do sistema proposto, de modo que consigam nele intervir e transformar conforme suas necessidades. Ainda sabemos muito pouco sobre os aspectos mais íntimos de como o autismo afeta os autistas, mas atualmente podemos encontrar ferramentas para que eles possam falar diretamente com os outros de maneiras pouco convencionais. Esse sistema é proposto como mais uma dessas possibilidade de comunicação, se inspirando em histórias como a de Carly, uma jovem autista não-verbal que a partir dos 11 anos de idade passou a se comunicar digitando em um computador (Fleischmann \& Fleischmann, 2012).

Devido às dificuldades motoras, tem-se visto o computador como alternativa à alfabetização tradicional, para que essas crianças tenham menos limitações para se comunicar. Assim, a partir do momento em que Carly passou a digitar como uma forma de comunicação fluente, ela conseguia compartilhar o que pensava e o que sentia, sem a limitação imposta pelo seu corpo: ela só precisava de uma ferramenta. Esse movimento tem acontecido pela Internet e é possível encontrar diversos blogs escritos por autistas, com o objetivo de compartilhar seu modo de vida.

\section{0 artefato proposto}

Com o intuito de concretizar o sistema projetado, escolheu-se trabalhar com um recorte de aplicação e selecionar um artefato para ser detalhado. Com isso, entende-se que se torna possível validar hipóteses de interação para saber se o sistema está adequado ao contexto delimitado (Saffer, 2010).

Foram pesquisadas diversas soluções que pudessem agregar em relação à manipulação de superfícies, elementos de linguagem, sintaxe e storytelling (Quesenbery \& Brooks, 2010), representadas pela Figura 3. As principais referências para esse artefato levavam em conta a estimulação sensorial, a visualização de dados não linear e a flexibilidade de interpretação. 


\section{CIDI 2017

Figura 3: Principais referências: mapas de histórias, referências de materiais táteis e dados para contar histórias.

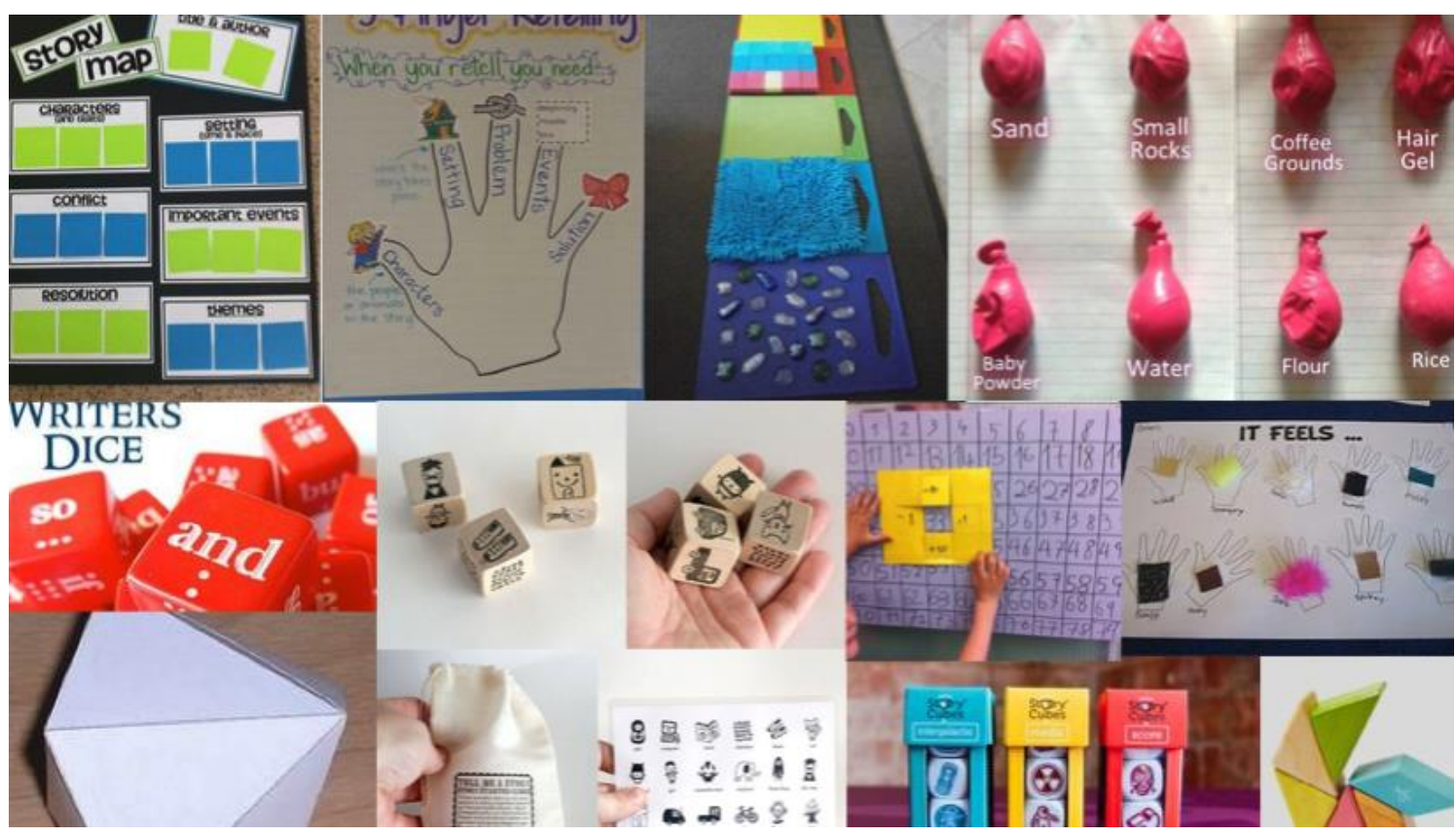

A partir dessas referências, a fase de ideação do projeto ocorreu paralelamente com dois objetivos: gerar suportes possíveis para o sistema e gerar o seu conteúdo. A proposição de suportes teve como resultado as peças que serão apresentadas posteriormente, e a geração de conteúdos deu origem aos itens componentes de cada peça.

Para proporcionar uma diversidade de formas e encaixes possíveis, assim como manter a flexibilidade de montagem, trabalhou-se com peças em forma de triângulos equiláteros ligadas por discos. A decisão se mostrou adequada também pela facilidade de coordenação motora, pois as peças não precisariam ser encaixadas com perfeição. Ao gerar esse microssistema, foi possível definir duas versões: uma versão que poderia ser produzida industrialmente e uma versão que poderia ser impressa em casa e complementada com materiais simples e disponíveis. Todas as peças têm $6,5 \mathrm{~cm}$ de altura e $7,5 \mathrm{~cm}$ de largura, sendo que o kit básico é formado de 50 peças e 30 discos, conforme a Figura 4.

Figura 4: Modelos de peças disponíveis e discos de ligação.

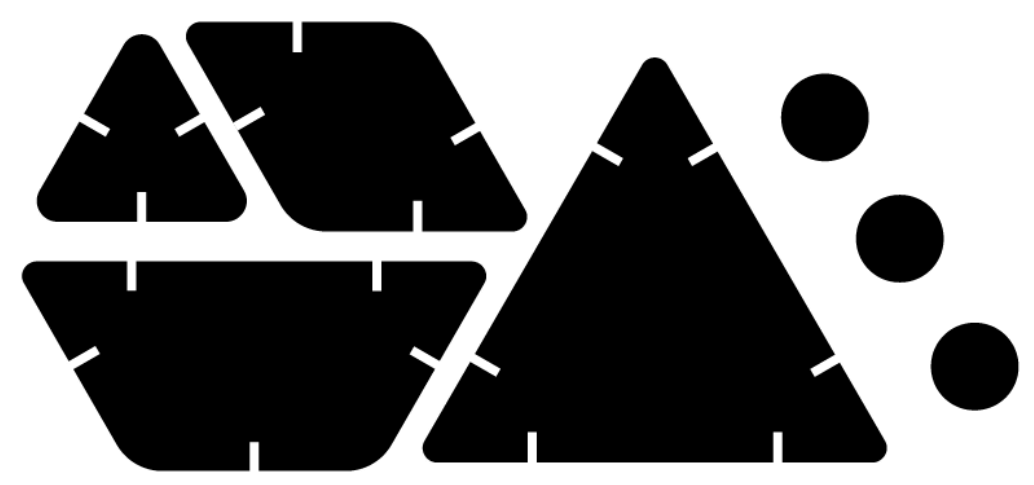

O conjunto básico foi montado a partir dos elementos essenciais para uma narrativa (Figuras 5 e 6) e das estimulações sensoriais possíveis nesse primeiro momento (Figuras 7, 8 e 9). O intuito é que as peças básicas tenham um caráter menos figurativo e mais abstrato, para complementar principalmente a comunicação não-verbal, visto que os aplicativos e produtos baseado no PECS cumprem bem essa função. Também foram idealizadas peças especiais que podem sofrer interferência direta da criança manipulando o artefato (Figura 10). 


\section{CIDI 2017

Figura 5: Signos de elementos que compõem a história (12 peças): início, fim, personagem, objeto, evento, cenário, ação, sentimento, pensamento, fala, conflito e solução.
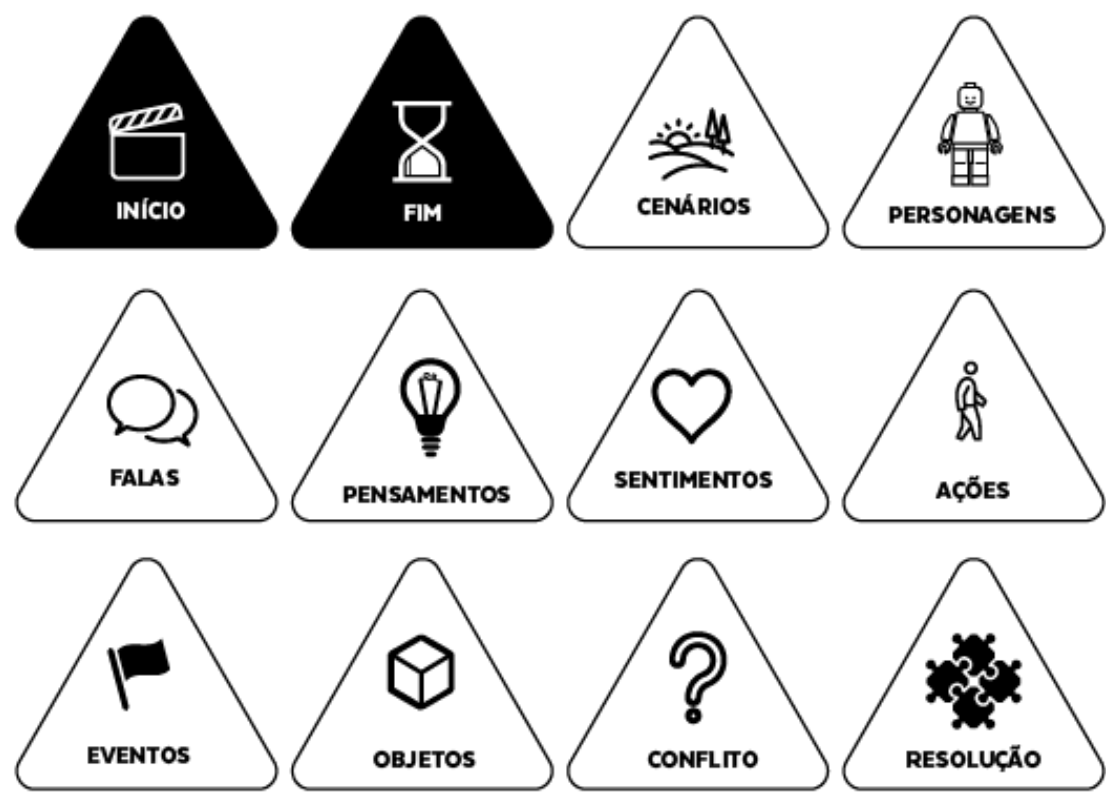

Figura 6: Conectivos (8 peças): exclamação (!), ponto final (.), reticências (...), interrogação (?), "e”, "ou”, "não", “mas".
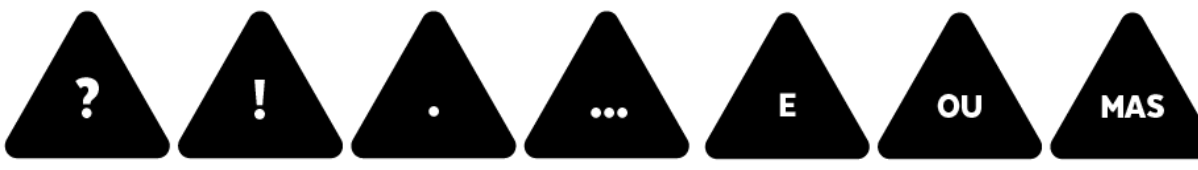

Figura 7: Elementos de Textura (6 peças): rugoso, gel, grama artificial, algodão, cabelo e areia.
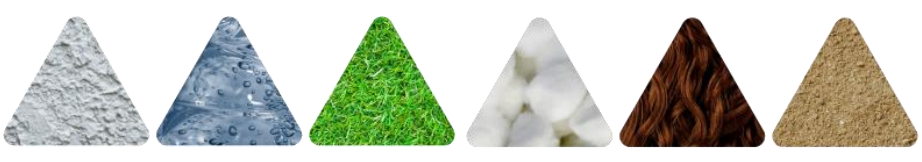

Figura 8: Elementos de Cor (9 peças): azul, vermelho, amarelo, verde, preto, transparente, dourado, prata, espelhado.
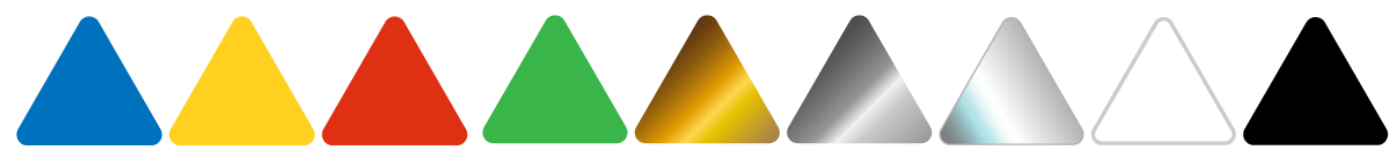

Figura 9: Elementos de Formas (8 peças)

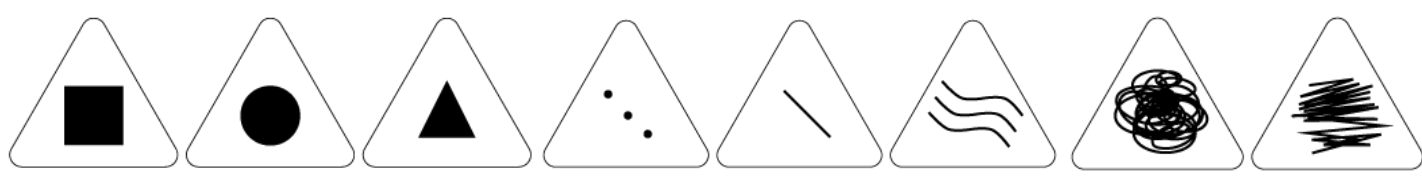




\section{CIDI 2017

Figura 10: Peças especiais: contando com 2 peças para desenhar personagens, 2 triângulos brancos e 3 peças especiais, totalizando 7 peças. Cabeça e corpo para a criança desenhar em cima personagens, em branco com cores diferentes, plastificado para desenhar com caneta de quadro branco, que apaga com fricção ou giz de cera.

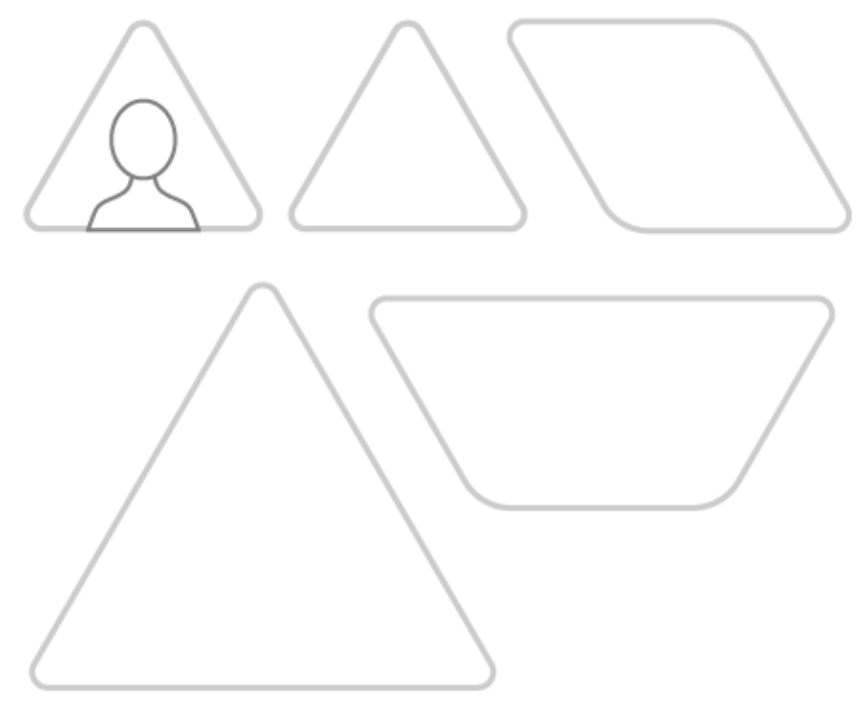

A partir de observações globais em um primeiro teste, além dessas peças, também se propôs a criação de kits temáticos que poderiam ser mais genéricos como "dinossauros" ou "animais", ou mais específicos como filmes, programas de TV, tipos de carros, entre outros. Assim, seria possível adequar o conteúdo com os interesses da criança. Como a proposta do sistema é aberta, isso também possibilita futuras colaborações e a confecção de peças pelos próprios usuários do artefato.

Com o intuito de disponibilizar esse modelo para um público mais amplo, visando as pessoas que almejam construir novos tipos de peça, ou mesmo que queiram criar um conjunto de peças personalizado a baixo custo, foram criados possíveis modelos para impressão caseira comum, em papel A4 (Figura 11). Ainda, o sistema permite a confecção de peças irregulares, mas que se encaixem com as outras peças. Em vez da ligação das peças ser realizada com discos, o papel pode ser cortado, dobrado e colado do modo que a criança quiser (Figura 12).

Todo esse conjunto pode ser impresso em casa e montado em qualquer superfície, sem a necessidade de ferramentas sofisticadas ou a ajuda de um adulto durante todos os momentos. Por se tratar de modelos simples, também é possível que os usuários criem conjuntos diferentes, com desenhos à mão ou com softwares de edição de vetores ou fotos, e compartilhem com outros usuários, criando uma comunidade que pode se desenvolver de maneira livre e orgânica, sem a necessidade de uma entidade gestora.

Figura 11: Exemplos de peças diferentes com conteúdo criado.

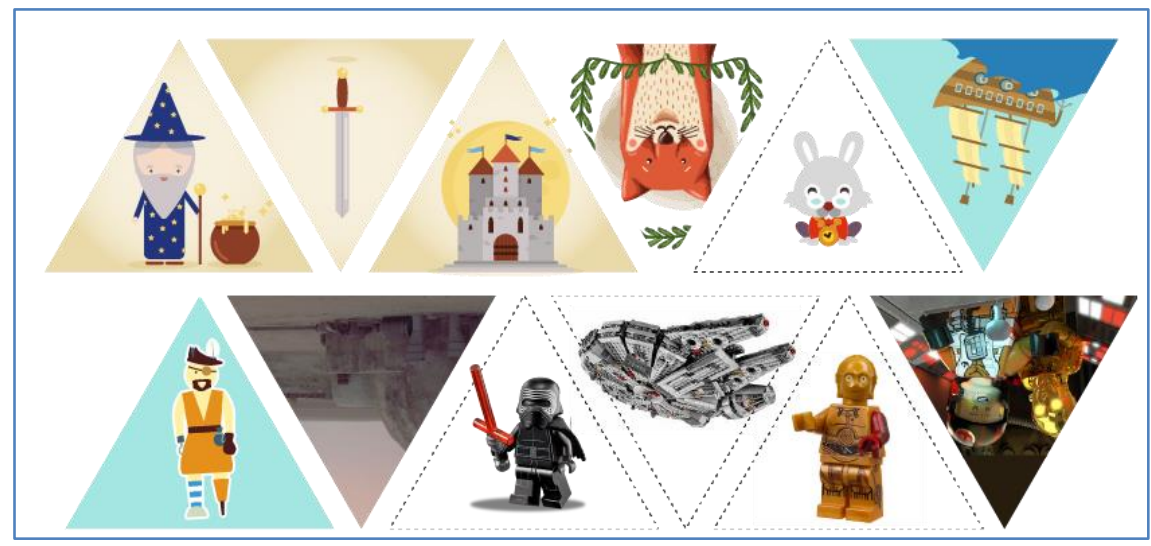


Figura 12: Exemplos de malhas que poderiam ser impressas para auxiliar na montagem das peças

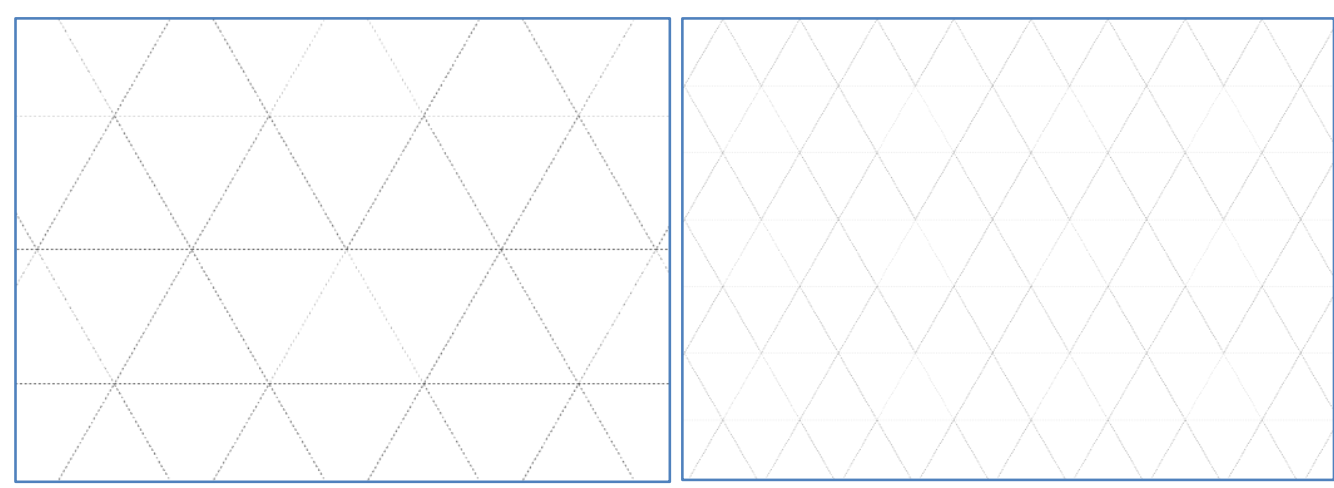

A partir das peças propostas, sugere-se que esse sistema aberto de comunicação favoreça a autonomia de expressão da criança autista. Esperamos que os elementos principais do sistema fomentem a estrutura narrativa da criança, enquanto os elementos mais abstratos, como as texturas apresentadas, possam permitir a expressão de sentimentos e percepções que geram um maior nível de dificuldade para a criança autista.

Assim, entende-se que a abordagem e o sistema proposto são maiores do que as peças que o concretizam. Entretanto, somente a partir das peças propostas que as próximas etapas de avaliação podem ser conduzidas. Já foram realizados testes iniciais exploratórios de observação de uma criança interagindo com o sistema. Espera-se validar a proposta em uma nova fase de entrevistas com a professora Joana, que acompanhou a realização do projeto. Após a fase de validação, a expectativa é continuar a avaliação e redesenho do sistema em contexto de sala de aula, conduzido e mediado pela professora Joana em seu contexto de trabalho.

\section{Considerações}

A voz de pessoas como Carly (Fleischmann \& Fleischmann, 2012), Emma (Zucher-long, 2016), Grandin (2013) e Lawson (2008) são essenciais para se entender a realidade dos indivíduos autistas e como podemos projetar um mundo que seja mais acolhedor para todos. A partir dessa riqueza de contos, vê-se a importância de se criar plataformas para potencializar a voz de crianças autistas.

O pensamento de design dentro da escola traz à luz várias possibilidades de intervenções positivas. O Design, enquanto abordagem, se mostrou bastante adequado em um contexto em que é necessário observar tanto o nível macro (o sistema e suas variáveis) quanto o micro (as pessoas e suas individualidades)(Kolko, 2011; Polaine et al., 2013). A partir da concepção de um sistema e de um artefato que o concretize, foi possível aplicar o processo de design em um contexto altamente complexo.

Ao enxergar a figura do designer como mediador da criação da realidade (Willis, 2006), vêse a necessidade de se criar sistemas que sejam distribuídos e capazes de evoluir organicamente, contando com a colaboração de qualquer pessoa que se envolva no processo (pais, estudantes, pedagogos entre outros), não somente projetistas. O sistema, portanto, deve evoluir juntamente com tudo aquilo que o compõe, de uma maneira descentralizada, emergente, em que todos os atores têm participação e voz, principalmente seu centro: os autistas. Com isso, acreditamos que seria possível uma diversidade de serviços inclusivos que que fossem compatíveis com a diversidade de jeitos de pensar desses indivíduos neuroatípicos.

\section{Referências}

ALVES, Rubens. 2001. A escola com a qual sempre sonhei sem imaginar que pudesse existir. Campinas: Papirus. 
BLUME, Harvey. 1998. Neurodiversity: on the neurological underpinnings of geekdom. The Atlantic. <http://www.theatlantic.com/magazine/archive/1998/09/neurodiversity/305909/>, recuperado 18 de junho de 2017.

FLEISCHMANN, Arthur; FLEISCHMANN, Carly. 2012. Carly's voice : breaking through autism. Touchstone/Simon \& Schuster. Recuperado 18 de junho de 2017.

GRANDIN, Temple. 2013. The Autistic Brain: Helping Different Kinds of Minds Succeed. New York: Mariner Books.

GRATIOT-ALFANDÉRY, H. 2010. Henrí Wallon. Recite: Editora Massangana.

HOGENBOOM, M. e B. WOODWARD. 2013. Autism: A holistic approach. $3^{\circ}$ ed Edinburgh: Floris Books.

IVIC, I. 2010. Lev Semionovich Vygotsky. Recife: Editora Massangana.

KLIN, Ami. 2006. Autismo e síndrome de Asperger: uma visão geral. Revista Brasileira de Psiquiatria 28(SUPPL. 1):3-11.

KOLKO, Jon. 2011. Exposing the magic of design : a practitioner's guide to the methods and theory of synthesis. Oxford University Press..

KURZWEIL, Ray. 2005. The Singularity is Near: when humans transcend biology. London: Duckworth Overlook.

LAWSON, Wenn. 2008. Concepts of normality: the autistic and typical spectrum. Jessica Kingsley.

LUENGO, Fabiola Colombani. 2010. A vigilância punitiva: a postura dos educadores no processo de patologização e medicalização da infância. Revista de Psicologia da Unesp 8:122-26. Recuperado <http://books.scielo.org/id/sw26r>, 18 de junho de 2017.

MCPARTLAND, J. C.; KLIN, A.; VOLKMAR, F. R. 2014. Asperger's syndrome: Acessing and Treating High-functioning Autism Spectrum Disorder. $2^{\circ}$ ed New York: Guilford Publications.

PACHECO, José, R. EGGERTSDÓTTIR, e G. L. MARINÓSSON. 2007. Caminhos para a Inclusão: um guia para o aprimoramento da equipe escolar. Porto Alegre: Artmed.

PACHECO, Raquel P. e SILVA, Tiago Barros Pontes e. 2015. As contribuições da abordagem de design para o ensino de crianças autistas. P. 1529-33 in Proceedings of the 7th Information Design International Conference. São Paulo: Editora Edgard Blücher. Recuperado 23 de abril de 2017 (http://www.proceedings.blucher.com.br/articledetails/20339).

PACHECO, Raquel Pereira. 2016. "Empatia para quê? Contribuições do design para o ensino de crianças autistas". Universidade de Brasília, Brasília.

POLAINE, Andrew; LøVLIE, Lavrans; REASON, Ben. 2013. Service design : from insight to implementation.

QUESENBERY, Whitney; BROOKS, Kevin. 2010. Storytelling for user experience : crafting stories for better design. .

RIOS, Clarice; ORTEGA, Francisco; ZORZANELLI, Rafaela; NASCIMENTO, Leonardo Fernandes. 2015. Da invisibilidade à epidemia: A construção narrativa do autismo na mídia impressa brasileira. Interface: Communication, Health, Education 19(53):325-35.

ROGERS, Carl R. 1961. On Becoming a Person. London: Constable \& Company.

ROGERS, Carl R. 1983. Freedom to learn for the 80's. $2^{\circ}$ ed Collumbus: Merrill.

SAFFER, Dan. 2010. Designing for Interaction: Creating Innovative Applications and Devices. $2^{\circ}$ ed Beryeleu: New Riders.

SAGRADO, A., R. PEREZ, e A. LIMA. 2014. Quando sinto que já sei. Brasil.

SAVIANI, Dermeval; ALMEIDA, Jane Soares de; SOUZA, Rosa Fátima de; VALDEMARIN, Vera Teresa. 2014. O legado educacional do século XX no Brasil. $3^{\circ}$ ed Campinas: Autores Associados. 
SOLOMON, Andrew. 2013. Love, No Matter What.

<https://www.ted.com/talks/andrew_solomon_love_no_matter_what?>, recuperado $18 \mathrm{de}$ junho de 2017.

STICKDORN, M. e J. SCHNEIDER. 2011. This is Service Design Thinking. Hoboken: Wiley \& Sons.

VIANNA, Carlos Eduardo Souza. 2006. Evolução histórica do conceito de educação e os objetivos constitucionais da educação brasileira. Janus 3(4).

WILLIS, Anne-Marie. 2006. Ontological Designing — laying the ground. Design Philosophy Papers.

ZUCHER-LONG, Emma. 2016. Emma's Hope Book. Recuperado <https://emmashopebook.com/>, recuperado 18 de junho de 2017.

\section{Sobre o(a/s) autor(a/es)}

Raquel Pereira Pacheco, Bacharela em Design, Universidade de Brasília (UnB), Brasil <rppacheco@live.com>

Tiago Barros Pontes e Silva, PhD, Universidade de Brasília (UnB), Brasil <tiagobarros@unb.br> 